\title{
Educação infantil entre os povos indígenas na perspectiva dos territórios etnoeducacionais
}

\author{
Child education among indigenous peoples \\ from the perspective of ethno-educational territories
}

\section{Educación infantil entre los pueblos indígenas}

en la perspectiva de los territorios etnoeducativos

RESUMO: O objetivo deste artigo é discutir a educação infantil indígena perpassada pela abordagem dos territórios etnoeducacionais. A metodologia da pesquisa é bibliográfica e os resultados são apontamentos de reflexões desafiadoras ao tema em estudo que culminem numa potencial contribuição em políticas públicas educacionais voltadas à educação escolar infantil indígena.

Palavras-chave: Educação infantil indígena. Territórios etnoeducacionais. Infância e criança.

\begin{abstract}
ABSTRAT: the objective of this article is to discuss the education of indigenous children beyond the approach of the ethno-educational territories. The methodology of the research is bibliographical and the results are challenging reflections of the theme under study that culminate in a potential contribution in public education policies directed to school education of indigenous children.

Keywords: Indigenous children's education. Ethno-educational territories. Childhood and child.
\end{abstract}

RESUMEN: El objetivo de este artículo es discutir la educación infantil indígena atravesada por el abordaje de los territorios etnoedu-

* Pedagogo e licenciado em Matemática. Especialista em Gestão Educacional. Mestre em Educação pela Universidade Federal de São Carlos. Doutor em Educação Escolar Universidade Estadual de São Paulo. Docente e pesquisador na Universidade Federal de Goiás, Regional Jataí. E-mail: claudionorsil@gmail.com. 
cativos. La metodología de la investigación es bibliográfica y los resultados son apuntes de reflexiones desafiantes al tema en estudio, que culminan en una potencial contribución en políticas públicas educativas dirigidas a la educación escolar infantil indígena.

Palabras clave: Educación infantil indígena. Territorios etnoeducativos. Infancia y niño.

\section{Introdução}

temática escolar indígena, sobretudo a educação de crianças, perpassa a polí-
tica pública educacional brasileira (as diretrizes nacionais curriculares para
a educação básica; diálogos entre o estado brasileiro e os povos indígenas), a pedagogia (processos de ensino-aprendizagem e currículo) e os direitos (a garantia de uma educação escolar diferenciada inscrita na Constituição Federal do Brasil).

Retratos da Escola publicou artigos em português e espanhol, tratando exclusivamente da temática indígena e a educação escolar sob o enfoque das políticas públicas. Luciano (2013) abordou o tema da educação escolar indígena na realidade das aldeias e mostra avanços e tensões em relação à implementação das políticas, sobretudo as tensões entre o que o estado quer impor e o que os povos indígenas querem, em respeito à sua cultura e realidades ancestrais e atuais. Lira, Silva e Salustiano (2014) trazem uma discussão sobre a educação escolar indígena, fundamentalmente, em termos das políticas públicas que tratam da escolarização. Criticam, pontualmente, a ineficácia e não efetividade da maior parte destas políticas que, mesmo quando implementadas, não se traduzem em realidade; só se tornam efetivas com luta e resistência, fruto dos esforços das próprias comunidades indígenas através do acesso de suas lideranças aos conhecimentos e aos "domínios" político-governamentais, locais e regionais, em que se faz prevalecer suas respectivas forças culturais e poder decisório. Nascimento (2013) faz uma discussão sobre os territórios etnoeducacionais, que é também a proposta deste artigo. A autora defende com muito rigor a efetividade de uma educação diferenciada, intercultural e bilíngue, como apontado no Decreto n.. 6.861, de 27 de maio de 2009, que institui a política dos territórios etnoeducacionais (Brasil, 2009 a) e que será apresentado com detalhes na segunda seção deste artigo.

A relação e a articulação destes trabalhos já publicados na revista Retratos da Escola com a produção do presente artigo é a continuação do debate em termos de políticas públicas que recaem sobre a educação infantil indígena e é opcional às comunidades, mas na sua constituição, se sugere que as redes de ensino assegurem os princípios da especificidade deste currículo, a especificidade do projeto pedagógico (PPP) destas escolas. 
Outro ponto de articulação é o aprofundamento da luta (ou lutas) pela educação infantil indígena, na busca de pedagogias emancipatórias em que os territórios etnoeducacionais sejam uma possível base de "pedagogia(s)". Será a primeira vez que a revista trará o tema na especificidade da educação infantil aos povos indígenas, no âmbito da educação escolar indígena (Brasil, 2013), a ser comentada ao longo das próximas seções. Trata-se de um trabalho que ultrapassa a revista Retratos da Escola, pois será uma contribuição à educação brasileira e às políticas educacionais.

A metodologia da pesquisa é bibliográfica, segundo Sampieri; Collado; Lúcio (2006). Para estes autores, a pesquisa bibliográfica " [...] consiste em identificar, obter e consultar a bibliografia e outros materiais que sejam úteis para os objetivos de estudo (SAMPIERI; COLLADO; LÚCIO, 2006, p.54). A metodologia permite que sejam organizados, como resultados da pesquisa, a construção de uma análise crítica na e da temática em estudo e, principalmente, encaminhamentos para novas pesquisas.

Neste artigo, se está diante de uma temática de luta por uma educação infantil voltada para as crianças indígenas brasileiras, por uma educação de qualidade que una aos conhecimentos dos povos indígenas os saberes e tecnologias da sociedade envolvente, respeitando, acima de tudo, as decisões destes povos, em aceitar ou não a educação escolar oferecida, que assume a diferenciação e garante direitos convencionalmente acordados mundialmente; e, no caso brasileiro, acordados na Constituição Federal de 1988.

Sociedade envolvente ou "sociedade nacional" é um termo político e de luta das comunidades indígenas e muito recorrente nos textos antropológicos e etno-históricos (Silva; Ferreira, 2001; Silva; Macedo; Nunes, 2002; Tassinari, 2007), indicando resistência e luta quanto à diferenciação e demarcação espacial e cultural dos povos indígenas em relação aos estados-nação em que estão territorialmente organizados e localizados, mas, não só territorialmente, mas cultural, tecnológico, socialmente, sem possuir ou acessar, por exemplo, serviços públicos como saúde, educação, segurança etc.

É importante, neste momento, embora seja efetuada a reflexão necessária, na segunda seção do artigo, que a educação infantil, enquanto política pública (BRASIL, 2009; 2010; 2013) esteja diretamente ligada à especificidade da educação infantil indígena. Brasil (2010) assevera, no item 9:

Garantida a autonomia dos povos indígenas na escolha dos modos de educação de suas crianças de 0 a 5 anos de idade, as propostas pedagógicas para os povos que optarem pela Educação Infantil devem:

Proporcionar uma relação viva com os conhecimentos, crenas, valores, concepções de mundo e as memórias de seu povo;

\section{$[\ldots]$}

Dar continuidade à educação tradicional oferecida na família e articular-se às práticas socioculturais de educação e cuidado coletivos da comunidade (BRASIL, 2010, p. 23). 
A educação infantil indígena nas Diretrizes Curriculares Nacionais (Brasil, 2009b, 2010; 2013) é um direito das comunidades e povos indígenas do Brasil. Contudo, respeita- se a escolha/decisão da comunidade, o que confere autonomia aos povos indígenas quanto à educação que ser quer dar aos seus filhos e filhas, pequenos e pequenas.

A ênfase dada neste artigo é considerar os territórios etnoeducacionais, termo oriundo do Decreto n.. 6.861(Brasil, 2009), para além de uma política pública; considerar os territórios etnoeducacionais como direcionamento para a amplificação das categorias infância e criança, numa perspectiva indígena, e também um direcionamento metodológico ao currículo, na construção de materiais didáticos; e um direcionamento também a produtos educativos e a projetos de pesquisa e extensão, que se unem e se articulam em um projeto etno social das comunidades e povos indígenas, principalmente, no que se refere ao sistema educacional brasileiro, concretizado na Lei de Diretrizes e Bases da Educação Nacional (LDBEN/Brasil, 1996), atualizada na Lei 12.796/2013, que acrescenta outros 36 dispositivos, como comenta Carneiro (2015).

Diante destas proposições, o objetivo deste texto é problematizar a temática da educação escolar de crianças indígenas sob a perspectiva da abordagem dos territórios etnoeducacionais; se considera e se arrisca a afirmar que esta abordagem garante a possibilidade de um estudo sob a perspectiva da sociologia da infância, como será indicado na reflexão desafiadora 3, ao final deste artigo, uma vez, que a sociologia da infância (Pinto; Sarmento, 1997) defende a especificidade da infância em contextos. Por exemplo, no caso brasileiro, não há uma única sociologia da infância voltada para uma criança única, linear, homogênea. A criança do espaço urbano vive uma infância diversa, neste mesmo espaço, se está no centro da cidade ou num condomínio fechado. Assim, há um vasto campo para estudos de uma sociologia da infância voltada para as crianças indígenas, para cada povo, para cada comunidade. O principal demarcador (Pinto; Sarmento, 1997) é o deslocamento do pensamento colonizador e a produção de uma identidade do ponto de vista do colonizado. Nessa linha é que o presente artigo encaminha desafios de pesquisas que tomem como foco as crianças indígenas e seu protagonismo, sua cultura própria em dinamização com as aprendizagens ancestrais.

Para tanto, se empreende, na primeira seção, uma discussão sobre educação infantil indígena, a partir das Diretrizes Curriculares Nacionais Gerais para a Educação Básica (Brasil, 2013) e a questão da diferenciação desta educação para as comunidades e povos indígenas brasileiros, destacando o PPP dessas escolas.

Na seção seguinte se faz a discussão teórica sobre os territórios etnoeducacionais e se adota esta perspectiva para pensar as categorias infância e criança indígenas, bem apontando sempre para a diferenciação do currículo das escolas.

Nas considerações finais, se tecem algumas reflexões desafiadoras sobre infância e criança indígena, bem como sobre o currículo das escolas para crianças indígenas, 
respeitando cada povo em sua singularidade e partindo dos pressupostos dos territórios etnoeducacionais.

Propõe-se que estas reflexões desafiadoras sejam motivação de pesquisa para se pensar a máxima de que existe uma categoria de infância e criança que implicam um currículo; e, também, categorias que assumam e contextualizem os povos indígenas brasileiros e para cada comunidade indígena, em particular; por isso mesmo, a educação infantil proposta e pensada deve ter sua especificidade, que não está desvinculada, nem fragmentada, muito menos afastada das categorias infância e criança de qualquer outro lugar do mundo, pois se admite uma infância que se caracteriza em diversos contextos geográficos, sociais, econômicos, políticos, uma infância que é construída histórica e socialmente, bem como geográfica, politica e em uma perspectiva étnica.

\section{A garantia da diferenciação no currículo da educação escolar indígena infantil}

O decreto que institui os territórios etnoeducacionais (Brasil, 2009a) é uma construção democrática e coletiva, sendo ouvidas as comunidades indígenas, os entes federados, a Fundação Nacional do Índio (Funai), a Comissão Nacional de Educação Escolar Indígena (CNEEI ), os conselhos estaduais de educação escolar indígena e a Comissão Nacional de Política Indigenista (CNPI).

Quanto aos objetivos dos territórios etnoeducacionais (Brasil, 2009a), eles se sintetizam na valorização da cultura dos povos indígenas e suas respectivas identidades; o fortalecimento da língua materna; formação de professores indígenas para escolas indígenas; currículos diferenciados com material didático específico para cada povo/nação (Artigo 2. ${ }^{\circ}$, incisos I a VI).

$\mathrm{O}$ artigo $7^{\circ}$ do Decreto exige para cada território etnoeducacional um plano de ação para a educação escolar indígena submetido à aprovação e conhecimento da comunidade. Sobre o plano de ação, este contempla desde diagnósticos até planejamento e organização das ações de implementação do território etnoeducacional.

Os territórios etnoeducacionais, para Silva (2016a) são um instrumento para produção de conhecimento indígena, eminentemente indígena e produzido por indígenas. E, em se tratando de educação escolar indígena, o autor indica e defende que o Decreto que institui os territórios etnoeducacionais dispõe, dentre outros elementos, de uma quase “imposição" para que se apresente uma didática específica à educação indígena, que não pode ser a didática da pedagogia contemporânea, geralmente europeizante, elitista, clássica e urbana. Talvez a didática intercultural de Candau (2012) apresente algumas aproximações ao caráter diferenciado para o currículo da educação escolar indígena infantil. A aproximação foi apontada por Silva (2015) e é resumida em quatro ações: desconstruir, articular, resgatar e promover. Essas ações definem uma didática intercultural. 
Outro elemento apontado por Silva (2016a) na questão intercultural ligada aos territórios etnoeducacionais: a formação de professores não pode se dar no interior das Diretrizes Curriculares das licenciaturas dos documentos oficiais do Ministério da Educação; ao contrário, devem se dar no âmago do que vem se convencionando chamar de licenciaturas interculturais, pois se destinam a territórios etnoeducacionais.

A definição de "território" indígena dada por Urquiza; Nascimento (2013), que dá sentido ao conceito de "territórios" etnoeducacionais, advém do Artigo 231 da Constituição Federal de 1988: construção, vivência, cultura, espaço físico, simbologia, cosmologia etc.

Isso implica a consideração de que, para os povos indígenas, terra não é subsistência, apenas, representa a vida, a vida social e religiosa. Portanto, está para além da relação com a natureza e do contato com a terra que dá o sustento da vida em sociedade; diz respeito também ao "bem viver", como já comentado anteriormente.

Os artigos 231 e 232 da Constituição Federal de 1988 também subsidiam o ideal dos territórios etnoeducacionais, na medida em que explicitam o reconhecimento à diferenciação dos povos indígenas brasileiros.

Os direitos territoriais conferem, assim, aos povos indígenas um espaço significativo de conquista e que vem acontecendo desde os anos 1980, com o "movimento indígena brasileiro". "Tal movimento se constituiu em um esforço comum e articulado de povos e lideranças indígenas no sentido de construir uma agenda pela terra, pela saúde, pela educação e outros direitos (GUTIERREZ, 2013, p. 285)".

Gutierrez (2013) nos ajuda a pensar o aprofundamento da noção de "território" e "territorialidade", sobretudo, para maior clareza dos territórios etnoeducacionais e como se configuram à educação infantil indígena. Gutierrez (2013) afirma, com base no artigo 231 da Constituição Federal, que a jurisdição da proteção da terra indígena, parte da concepção de que a terra é tudo para a existência e continuação das gerações.

Outros autores ajudam a organizar a proposição de Gutierrez (2013) sobre território e territorialidade. Territorialidade ultrapassa a noção de território. Território é aquilo que está instituído (Raffestin, 1993), a terra, o sustento, a continuidade das gerações no local demarcado e onde se constrói a identidade étnica, a identidade de pertencimento. Territorialidade (Sack, 1993; Raffestin, 1993) tem duas implicações: a primeira, de defesa ou proteção do espaço; a segunda, de conquista de novos espaços ou reconquista, para não se perder o que já se tem. Ambas as implicações são, fundamentalmente, místicas, principalmente para os povos indígenas. Territorialidade tem uma amplitude muito maior que território no sentido da relação do homem com a terra. Território seria a posse. Territorialidade seria a resistência em proteger o espaço e a cultura e reconquista de espaços perdidos, designando uma autonomia plena e uma identidade construída, denominada por Sack (1993) de identidade espacial.

A perspectiva dos territórios etnoeducacionais abre espaço para o entendimento, a partir das categorias território e territorialidade, de infância e criança, bem como, ao 
currículo da educação infantil indígena, sobretudo, amplia e diferencia estas categoriais, demonstrando a particularidade e especificidades dos povos indígenas brasileiros e sua relação com a terra, com a natureza e sua cosmovisão.

Sobre o primeiro ponto, as categorias infância e criança na educação infantil indígena ganham espaços de novos outros entendimentos, pois, a partir dos territórios educacionais, como afirmam Venere; Velanga (2008), se identificam e se categorizam crianças indígenas, que não são e jamais poderão ser homogêneas, pois pertencem a povos, nações diferentes. Não poderá haver para essas categorias uma psicologia da educação europeizante para explicar o desenvolvimento de crianças indígenas. Haverá de se formular uma cosmovisão indígena sobre infância e sobre criança, que conte, obrigatoriamente, com indígenas e seus sábios, com a participação ativa das crianças e seus modos de construção cultural, no interior da cultura a que pertencem e convivem.

Pinto; Sarmento (1997) pontuam a sociologia da infância ou o seu campo, como estudos que se efetivam a partir das crianças, das realidades de suas vivências. São protagonistas e autores(as) de suas vivências e percepções. Neste sentido, nas comunidades indígenas, enquanto categorias a serem construídas, a partir dos territórios etnoeducacionais, permitem-nos arriscar a afirmativa de que uma sociologia da infância acaba por emergir nessa nova construção que respeita e considera as prerrogativas antropológicas e da etno-história, no sentido de que categorias como criança e infância são e serão construídas a partir de cada povo e sua singularidade, logo, não haverá uma homogeneidade categorial ou conceitual, única, para todos os povos indígenas.

Defende-se que os territórios etnoeducacionais contribuem para a construção de infância e que há, de fato, um campo de estudos extremamente aberto às pesquisas sobre a educação infantil indígena representado e protagonizado pelas crianças indígenas brasileiras, como bem demonstram trabalhos como os de Silva; Macedo; Nunes, 2002, Tassinari, 2007, Coelho; Debortoli (2012); Silva (2013); Bergamaschi; Sousa (2015).

Mas vale uma observação fundamental: a produção de conhecimento nas categorias infância e criança não se pode efetivar sem o acumulado conjunto de pesquisas e produções no campo da antropologia e da etno-história. Esta afirmativa está apontada por Silva (2016a) quando trata dos territórios etnoeducacionais na formatação de produção de conhecimento na temática indígena.

\section{As diretrizes nacionais gerais para a educação escolar indígena}

As diretrizes da educação escolar indígena não estão desvinculadas das demais diretrizes educacionais, ou seja, das diretrizes de cada etapa da educação básica e respectivas modalidades presentes no documento Brasil (2013), publicado pelo Ministério da Educação. Assim, os pressupostos da educação escolar indígena atrelam-se às diretrizes da 
educação infantil, à modalidade da educação especial, à diretriz em direitos humanos na educação, e assim por diante.

A educação infantil indígena precisa ser assistida e garantida, sobretudo e fundamentalmente, numa perspectiva de educação escolar diferenciada. A sua organização sob os territórios etnoeducacionais é uma alternativa de gestão, mas também de pesquisa, no sentido de possibilitar uma produção de conhecimento, em termos de currículo, que assegure a educação diferenciada, mas, especialmente, que seja produzida por indígenas e suas respectivas comunidades.

Partindo para uma leitura nas políticas educacionais voltadas à educação escolar indígena, Brasil (2013), ao discorrer sobre os artigos 78 e 79 da Constituição Federal, defende que os currículos multiculturais exigem a participação efetiva da União. No Parecer 14/99 do Conselho Nacional de Educação (CNE) sustenta-se que as crianças podem ter acesso às informações e conhecimentos tecnológicos, ou seja, há direitos garantidos, para que as crianças indígenas tenham acesso aos mesmos serviços públicos educacionais das crianças do estado nacional brasileiro.

A seção 4 das Diretrizes da Educação Escolar Indígena (Brasil, 2013) destaca as etapas de escolarização, da educação infantil ao ensino médio e modalidades. Sobre a educação infantil, o documento afirma que esta etapa da educação básica é também pertinente aos povos indígenas, como direito e opção; as comunidades são livres para se organizarem, enquanto unidade de gestão escolar, asseguradas a sua cultura, sobretudo, sua cosmovisão sobre a educação de suas crianças, desde bebês.

O fator "escolha" pelas comunidades indígenas se elas desejam ou não a educação das suas crianças exige que os sistemas de ensino apresentem uma proposta oficial de construção de escola aos seus líderes (líderes dessas comunidades), ou seja, apresentem a oferta da educação infantil pública que se caracterizará diferenciada, o que implica que, junto aos conhecimentos científicos não indígenas, estarão presentes também os conhecimentos da comunidade e de sua cultura. A proposta pode ser na forma de um projeto político pedagógico ou outro modelo e, preferencialmente, que sua construção tenha sido empreendida em parceria com as pessoas da comunidade (BRASIL, 2013; CARNEIRO, 2015).

A proposta pedagógica para a educação escolar indígena voltada às crianças foi estabelecida pelo Parecer CNE/CEB n.ำ20/2009, marcado pela identificação de cada povo; a garantia, presente neste documento, é que estes povos acessem os conhecimentos científicos não indígenas, mais amplos, vivenciados nas redes de ensino públicas, municipais ou estaduais. Este acesso para os indígenas é forma de luta, resistência.

Um detalhe específico na proposta, defendida no Parecer de 2009 e presente nas Diretrizes Curriculares Nacionais (Brasil, 2013), e se trata de algo inegociável, é o respeito ao modo de vida das comunidades e o calendário escolar a ser utilizado, que se caracterizará diferenciado; um currículo organizado em brincadeiras e costumes ancestrais e um protagonismo infantil. 
A organização do trabalho pedagógico e a efetivação dos processos educativos trazem em destaque, dentre outros, a ênfase nas práticas culturais da comunidade; a presença de sábios da comunidade; presença das mães ou responsáveis pelas crianças nos assuntos relativos aos cuidados.

Assegurar às comunidades e aos povos indígenas o atendimento ao público da educação especial também atrelado à oferta de educação infantil pelo estado brasileiro. Oferecer atendimento com qualidade que respeita o poder decisório dos povos indígenas, visando os estudantes com deficiências, transtornos do desenvolvimento e altas habilidades, superdotação. Trata-se de um direito às crianças indígenas e à infância dos povos indígenas, que contam com a colaboração participativa dos professores e professoras indígenas, da opinião das famílias, do respeito à cultura dos respectivos povos, sobretudo, equipe multidisciplinar indígena e não indígena, seja dos órgãos normativos indígenas ou da equipe do sistema de ensino ou de saúde do estado, representado pelas instâncias federal, estadual ou municipal.

As prerrogativas da Resolução CNE/CEB n. $\stackrel{0}{2} / 2001$ apontam para o instituído na prerrogativa dos territórios etnoeducacionais (Brasil, 2009), a fim de ser pensadas e gestadas ao público da educação especial, uma produção de conhecimento própria para cada comunidade e para cada povo indígena, seja em termos de materiais, em atendimento educacional especializado, enfim, sempre em consentimento com os sábios e líderes das comunidades. Um levantamento de estudos sobre essa temática contribuiria para se conhecer como essa articulação entre a Resolução citada e os territórios etnoeducacionais pode se efetivar, na perspectiva de produção de conhecimento, como defende Silva (2016 a).

A atenção das Diretrizes Curriculares (Brasil, 2013) também está voltada para o destaque ao PPP das escolas em que se efetivará a educação diferenciada, por meio do currículo. O PPP é o documento que prevê a garantia da prerrogativa da diferenciação e, portanto, dos direitos das crianças indígenas.

O PPP para as escolas de educação infantil, sob a base dos territórios etnoeducacionais se resume a duas palavras-chave: bem-viver e diferenciação. O bem-viver está ligado à herança dos povos indígenas e seus projetos etno-societários. Diferenciação é a garantia da interculturalidade, multi(bi)linguismo, gestão própria (comunitária, por natureza, e especificidade das tradições dos povos indígenas) e, sobretudo, a raíz da territorialidade, em seu sentido amplo, para além do espaço geográfico, que abarca o contato com a sociedade envolvente e se finca nos princípios da sustentabilidade e o direito à terra, fundamentalmente, a luta pela terra (BRASIL, 2013).

Urquiza; Nascimento (2013) indica que territorialidade implica identidade dos povos indígenas e isto quer dizer que assumem seus próprios nomes, o nome de seus respectivos povos e não os nomes dados pelos brancos colonizadores.

Voltando ao PPP e sua relação com o currículo, Brasil (2013) defende que currículo é um instrumento normativo, que atende às especificidades dos processos de aprender 
e de ensinar, elaborados pelos sistemas de ensino; currículo que se exige diferenciado para os povos indígenas e para cada comunidade indígena. O PPP e, por conseguinte, o currículo necessitam ser pensados e elaborados a partir dos territórios etnoeducacionais, um projeto etno societário e etno-político para a educação infantil, que se inicia com a concepção de infância e criança indígenas.

Dos estudos das teorias do currículo, uma teoria se aproxima muito do currículo que se está defendendo neste artigo a partir dos territórios etnoeducacionais e dos documentos oficiais das diretrizes voltadas para a educação escolar indígena infantil. Trata-se da relação do currículo com a cultura popular. Para o espaço deste artigo, trata-se da cultura indígena.

Pensa-se, portanto, nesta perspectiva, uma pedagogia crítica e um currículo crítico, ou seja, uma escola indígena que se estrutura a partir da luta e nesta permanece por questões histórico-políticas, como defendem Giroux; Simon (2000), para quem a escola é um território de lutas e por isso a defesa de um currículo crítico.

Aspectos da interculturalidade, do empoderamento social e político estão presentes em Giroux; Simon (2000), bem como a configuração sobre o protagonismo infantil indígena no currículo e nas pesquisas sob o enfoque da sociologia da infância.

Pensar o currículo e a escola de educação infantil indígena não pode se dar sem a proposta desta pedagogia crítica, que apresenta os atores e lhes dá visibilidade no falar e apresentar seu posicionamento. Nesta perspectiva há a possibilidade de afastamento de uma pedagogia hegemônica, colonialista e pertencente a uma sociedade diferente da indígena, que carrega, sobretudo, a marca do preconceito e da discriminação, tanto étnica, quanto, fundamentalmente, religiosa e outros marcos que mantêm a subordinação e a subjugação dos povos indígenas.

A educação diferenciada está apoiada e garantida nos territórios etnoeducacionais (Brasil, 2009a; 2013), firmando-se como uma política educacional que engendra uma concepção de currículo diferenciado para a educação infantil, bem como, subsidia uma proposta de produção de conhecimento singular e especificamente indígena "demarcada", construída no território, na base da territorialidade que alcança o místico, uma concepção cosmológica da existência humana no universo - uma política etnoeducacional apresentada no Decreto n. ${ }^{\circ}$ 6.861/2009 (BRASIL, 2009 a).

\section{Reflexões desafiadoras - considerações finais}

As reflexões desafiadoras aqui organizadas, seguindo a metodologia da pesquisa bibliográfica proposta, nascem dos territórios etnoeducacionais e das propostas das diretrizes curriculares nacionais para educação infantil e para a educação escolar indígena, perpassando ainda as diretrizes operacionais para o atendimento educacional especializado na educação básica, modalidade educação especial. 
O conjunto destas diretrizes alinhadas aos territórios etnoeducacionais permite a construção de uma concepção de infância indígena e de criança indígena, bem como, a primeira aproximação a uma sociologia da infância, que destaca a infância indígena, que leva em consideração as comunidades e povos indígenas em sua respectiva singularidade.

O conjunto das diretrizes e a abordagem dos territórios educacionais permitem também outras problemáticas e discussões sobre o currículo da educação infantil para os povos indígenas brasileiros e comunidades indígenas, em particular que no âmbito da atual Base Curricular Comum, e aparenta ser uma questão a ser debatida por educadores indígenas e não indígenas.

A partir das discussões levantadas, sobretudo pelo princípio ou princípios dos territórios etnoeducacionais, são elencadas reflexões desafiadoras à educação infantil indígena, impulsionando ou motivando questionamentos e encaminhamentos de pesquisas e novas outras problemáticas, sobretudo, político-administrativas, aos sistemas de ensino e órgão normativos ligados aos povos indígenas brasileiros, bem como aos movimentos sociais indígenas e aos movimentos pró-infância, que se debruçam sobre o tema das políticas públicas em educação.

As reflexões desafiadoras são conceituadas e em seguida brevemente comentadas.

» Reflexão desafiadora 1. Esta reflexão traz como palavras-chave: direitos, luta e movimentos sociais. Traz-se aqui o pano de fundo histórico da questão indígena, sobretudo e, fundamentalmente, a terra. A terra, a propriedade, o território e a territorialidade (Sack, 1986; Raffestin, 1993; Gutierrez, 2013) não podem ficar de fora da formação etno-política e etno- societária das crianças indígenas. O PPP das escolas de educação infantil das comunidades indígenas deve assegurar esta premissa. Pesquisas que investiguem e fiscalizem, bem como denunciem efetividades ou não destas propostas precisam ser assumidas pelas comunidades indígenas e suas lideranças, bem como por parte dos órgãos normativos e gestores. Esta seria a primeira "onda" reflexiva, concluindo este artigo. Reflexão desafiadora que se pauta na luta pelos direitos das crianças indígenas à educação, juntamente com outros direitos, como saúde, por exemplo. Isto implica a revisão periódica dos direitos garantidos: políticas, investimentos, parcerias com as universidades e outros setores. Experiências bem sucedidas sendo divulgadas e compartilhadas tornariam as lutas pela educação infantil nas comunidades indígenas brasileiras ainda mais fortes. Sugere-se isso com uma certa urgência. Tais experiências e trocas de diálogos entre os povos indígenas e seus territórios etnoeducacionais, voltados às crianças, parecem ser uma boa continuidade no campo das resistências e lutas dos povos indígenas brasileiros. 
» A reflexão desafiadora 2 trata do pedagógico, que convém ser organizado a partir dos conceitos e categorias de infância indígena e de criança indígena que respeitam e singularizam cada povo e cada comunidade. Trata-se também de pesquisa educacional. Neste sentido, se reforça nesta reflexão desafiadora a ideia e a defesa de que os territórios etnoeducacionais contemplam o que se pode considerar uma sociologia da infância indígena no Brasil. A evidência desta "aposta" implica o mapeamento, de início, das categorias infância e criança que são e podem ser estudadas em cada povo indígena brasileiro, com forte apoio nos estudos antropológicos e etno-históricos já desenvolvidos há bem tempo no Brasil, com ricas contribuições ao campo educacional. Para citar alguns autores e seus respectivos estudos, tem-se Silva; Ferreira (2001), Silva; Macedo; Nunes, 2002, Tassinari, 2007 e Nötzold; Rosa; Bringmann (2012).

» Reflexão desafiadora 3. A nossa educação infantil urbana e com forte tendência europeizante ocidental não serve às comunidades e povos indígenas brasileiros. O currículo para a educação infantil, em discussão neste artigo, advoga um material didático específico e diferenciado - diferenciado em seu sentido amplo, sobretudo, com base nos territórios etnoeducacionais. Estamos a falar, portanto, de uma pedagogia intercultural, uma pedagogia para a educação escolar indígena. Neste aspecto, as pesquisas e a extensão universitárias, enfocando o protagonismo, tanto das comunidades, quanto de suas crianças, com base no bem-viver, a sustentabilidade e, sobretudo, a relação com a sociedade envolvente são grandes avanços para que esta proposta se consolide como desafio.

A contribuição deste artigo é o apontamento de uma das frentes de luta da educação infantil no Brasil, qual seja, a luta por uma educação infantil indígena de qualidade, pautada nos territórios etnoeducacionais - desde que a oferta desta educação infantil diferenciada seja aceita pelas comunidades indígenas brasileiras.

Um dos resultados do estudo é a máxima de que, pelos territórios etnoeducacionais, seja pensada e organizada uma educação escolar indígena infantil diferenciada, que tenha como produto final uma produção de conhecimento próprio à comunidade indígena, o que inclui outra didática; outra organização e gestão escolar, que não deve ser a réplica da escola da cidade, urbana e não indígena; outra pedagogia, que se mescla e se "diferencia" entre os conhecimentos dos povos indígenas e os conhecimentos e tecnologias externos aos territórios etnoeducacionais; uma pedagogia infantil de resistência e de luta, demarcada pela diferenciação, em seu sentido amplo e nas categorias infância, criança e currículo, numa (possível) perspectiva pautada na sociologia da infância.

As reflexões desafiadoras aplicadas à educação infantil indígena, apresentadas neste artigo, podem se constituir uma continuidade das lutas históricas dos povos indígenas 
brasileiros, tendo como ponto de partida e de chegada as políticas públicas, não apenas educacionais, mas todas as outras demandas de agenda pública federal. Uma pedagogia de resistência precisa ser dinâmica, no sentido de continuar a emergir, para que se configure, na contemporaneidade, a possibilidade de atuação destes novos atores, as crianças, demarcando, "por" e "com" suas subjetividades e autonomias - pedagogias emancipatórias fundadas nos territórios etnoeducacionais - bem como, participação em comunidade, o acesso aos instrumentos do colonizador para não se repetir e não se permitir a opressão, o silenciamento e a discriminação e, desta forma, desde a educação infantil indígena, se desenvolvam, na territorialidade, o pertencimento e a conquista da identidade e dos direitos dos povos indígenas brasileiros, como direitos que também pertencem às crianças não indígenas.

Recebido em: 07/02/2018 e aprovado em: 18/06/2018

\section{Referências}

BERGAMASCHI, Maria Aparecida; SOUSA, Fernanda Brabo. Territórios etnoeducacionais: ressituando a educação escolar indígena no Brasil. Pro-posições, Campinas: Unicamp, v. 26, n. 2 (77), p. 143-161, mai.-ago., 2015. Acesso em 25 abr. 2018.

BRASIL. Congresso Nacional. Lei n. ${ }^{9}$ 9.394, de 20 de dezembro de 1996. Estabelece as diretrizes e bases da educação nacional. Diário Oficial da União. Brasília, 1996.

Ministério da Educação. Secretaria de Educação Básica. Secretaria de Educação Continuada, Alfabetização, Diversidade e Inclusão. Secretaria de Educação Profissional e Tecnológica. Conselho Nacional da Educação. Câmara Nacional de Educação Básica. Diretrizes Curriculares Nacionais Gerais da Educação Básica. Ministério da Educação. Secretaria de Educação Básica. Diretoria de Currículos e Educação Integral. Brasília: MEC, SEB, DICEI, 2013, p. 354-394.

Ministério da Educação. Secretaria de Educação Básica. Diretoria de Concepções e Orientações Curriculares para a Educação Básica. Coordenação Geral de Educação Infantil. Diretrizes curriculares nacionais para a educação infantil. Brasília: MEC,SEB, 2010.

Presidência da República. Casa Civil. Subchefia para Assuntos Jurídicos. Decreto n.ำ 6.861, de 27 de maio de 2009. Dispõe sobre a Educação Escolar Indígena, define sua organização em territórios etnoeducacionais, e dá outras providências, 2009a.

. Ministério da Educação. Conselho Nacional de Educação. Câmara de Educação Básica.

Resolução n.o 5, de 17 de dezembro de 2009. Fixa as Diretrizes Curriculares Nacionais para a Educação Infantil, Brasília, 2009b.

CANDAU. Vera Maria (Org.). Didática intercultural: aproximações. Petrópolis: Vozes, 2012.

CARNEIRO, Moacir Alves. LDB fácil: leitura crítico-compreensiva, artigo a artigo.. Petrópolis: Vozes, 2015. 23ạ edição. 
COELHO, Luciano Silveira.; DEBORTOLI, José Alfredo Oliveira. Corporalidade e engajamento - Participação e aprendizado de crianças e adultos em contextos indígenas. 2012, p. 131-152. In: ARROYO, Miguel G.; SILVA, Maurício Roberto da (Orgs.). Corpo-infância: exercícios tensos de ser criança; por outras pedagogias dos corpos. Petrópolis: Vozes, 2012.

GUTIERREZ, José Paulo. O direito dos povos indígenas. In: URQUIZA, Antonio H. Aguilera (Org.). Culturas e história dos povos indígenas em Mato Grosso do Sul. Campo Grande: Editora UFMS, 2013, p. 281-304.

GIROUX, Henry A.; SIMON, Roger. Cultura popular e pedagogia crítica: a vida cotidiana como base para o conhecimento curricular. In: MOREIRA, Antonio Flavio; SILVA, Tomaz Tadeu da. Currículo, cultura e sociedade. São Paulo: Cortez, 2000.

LIRA, André Augusto Diniz; SILVA, Andréia Ferreira da; SALUSTIANO, Dorivaldo Alves. Povos indígenas e escolarização no Brasil. Retratos da Escola, Brasília: Esforc, v. 8, n.. $14,145-157$, jan.- jun., 2014.

LUCIANO, Gérsem José dos Santos. Educação indígena no país e o direito de cidadania plena.

Retratos da Escola, Brasília: Esforce, v. 7, n.ํㅜ 13, 345-357, jul.-dez., 2013.

NASCIMENTO, Rita Gomes de. Educação Escolar Indígena - políticas e tendências atuais. Retratos da Escola, Brasília: Esforce, v. 7, n.. 13, 333-344, jul.-dez., 2013.

NÖTZOLD, Ana Lúcia Vulfe; ROSA, Helena Alpini; BRINGMANN, Sandor Fernando. Etnohistória, história indígena e educação. Contribuições ao debate. Porto Alegre: Pallotti, 2012.

PINTO, Manuel; SARMENTO, Manuel Jacinto (Orgs.). As crianças: contextos e identidades. Braga: Universidade do Minho, 1997.

RAFFESTIN, Claude. Por uma geografia do poder. São Paulo: Ática, 1993.

SACK, Robert David. Human territoriality: its Theory and history. Cambridge: Cambridge University, 1986.

SAMPIERI, Roberto Hernandez; COLLADO, Carlos Fernández; LUCIO, Maria del Pilar Baptista. Metodologia de Pesquisa. São Paulo: Mcgraw-Hill, 2006.

SILVA, Claudionor Renato da. Notas pedagógicas étnicorraciais na temática indígena frente a 11.645/08. Para cursos de Pedagogia e Licenciatura Intercultural. Olinda: Livro Rápido, 2015.

. Considerações sobre os territórios etnoeducacionais e a produção do conhecimento em educação escolar indígena. In: MACHADO, Márcia (Org.). Cultura e história dos povos indígenas: formação, direitos e conhecimento antropológico. Fortaleza: Expressão Gráfica e Editora, 2016. p. 3960 .

SILVA, Aracy Lopes da; FERREIRA, Mariana Kawall Leal (Orgs.). Antropologia, história e educação. A questão indígena na escola. São Paulo: Global, 2001.

SILVA, Aracy Lopes da; MACEDO, Ana Vera Lopes da Silva; NUNES, Ângela (Orgs.). Crianças indígenas: ensaios antropológicos. São Paulo: Global, 2002.

SILVA, Rogério Correa da. Mau-olhado e quebranto: o que podemos aprender com os povos indígenas sobre suas crenças mesmo quando eles desconfiam de nossa educação infantil? In: SILVA, Isabel de Oliveira; SILVA, Aracy Alves Martins (Orgs.). Infâncias do campo. Belo Horizonte: Autêntica, 2013, p. 149-166. 
TASSINARI, Antonela. Concepções indígenas de infância no Brasil. Tellus, Campo Grande: UCDB, ano 7 , n. ${ }^{\circ}$ 13, p. 11-25, out., 2007.

URQUIZA, Antonio H. Aguilera; NASCIMENTO, Adir Casaro. Povos indígenas e as questões da territorialidade. In: URQUIZA, Antonio H. Aguilera (Org.). Culturas e história dos povos indígenas em Mato Grosso do Sul. Campo Grande: Editora UFMS, 2013, p. 53-72.

VENERE, Mario Roberto; VELANGA, Carmen Tereza. A criança indígena e a educação infantil: as complexas relações entre a cultura e a escola na cidade. Tellus, Campo Grande: UCDB, ano 8, n. 15, p.175-191, jul./dez., 2008. 